\title{
Adoption Level of Improved Goat Farming Technologies by Commercial Goat Farmers in Tamil Nadu, India
}

\author{
M. Gunaseelan ${ }^{1}$, B.P. Singh ${ }^{1 *}$, Med Ram Verma ${ }^{2}$ and K. Pachaiyappan ${ }^{1}$ \\ ${ }^{1}$ Division of Extension Education, ICAR-Indian Veterinary Research Institute, Izatnagar, \\ U.P.-243 122, India \\ ${ }^{2}$ Division of Livestock Economics, Statistics \& Information Technology, ICAR-Indian \\ Veterinary Research Institute, Izatnagar, U.P.-243122, India \\ *Corresponding author
}

\begin{abstract}
A B S T R A C T
A study was undertaken to assess the adoption level of commercial goat farmers under semi-intensive and intensive systems of management in Tamil Nadu. To this survey, a

Keywords

Adoption level, Commercial Goat farmers, Tamil $\mathrm{Nadu}$

Article Info

Accepted:

22 April 2018

Available Online:

10 May 2018 sample of 120 commercial goat farmers (20 farmers from each district) was selected randomly from 6 districts of Tamil Nadu. Data revealed that, overall 46.67 per cent of the commercial goat farmers had medium level of adoption of improved goat farming practices, followed by high $(33.33 \%)$ and low $(20.00 \%)$ extent of adoption. Average adoption indices of improved goat farming technologies were 60.71, 64.61, 76.19 and 67.20 for small, medium, large and overall categories of farmers, respectively. Overall adoption index of improve goat husbandry practices by the commercial goat farmers revealed that, housing practices obtained highest adoption index (74.41-I) followed by feeding (67.42-II), health care (66.00-III), breeding (65.33-IV) and general management practices $(62.81-\mathrm{V})$.Multiple linear regression analysis showed that, the factors viz., family income, investment on goat farming, flock size and economic motivation had positive and significant (1\% level) influence on the variability in adoption levels of commercial goat farmers. Education and system of management of goats showed positive and significant (5 $\%$ level) towards adoption of commercial goat farmers.
\end{abstract}

\section{Introduction}

Goats are among the main meat-producing animals in India, whose meat (chevon) is one of the choicest and has huge domestic demand across the country. Besides meat, goats provide other products like milk, skin, fiber and manure. India, with 135.2 million goats is one of the largest goat owning countries in the world and playing a significant role in livelihood and nutritional security as well as providing supplementary income to nearly 70 million farmers of over 5,00,000 remote villages (CIRG, Annual Report, 2015-16). However, the productivity of goats under the traditional production system is very low owing to their maintenance under extensive system on natural vegetation and shrinking common grazing lands and tree lopping. Moreover, adoption of improved technologies and management practices in the farmers' flock is very low (Singh and Kumar, 2007). 
Adoption behaviour of goat farmers depends on knowledge, economic motivation, family education status, extension agency contact, social participation and income (Kumar et al., 2014). The adoption is low in important scientific practices due to lack of exposure, henceforth extension agencies have to arrange training and demonstration programs of improved practices to goat keepers (Singh, 2017). Goat rearing using improved management practices undertaken for maximization of returns from the enterprise was considered as 'commercial goat farming' in the present context. The entry of large farmers, who have better access to technical knowledge, resources and market, into this activity would help in realizing the potential of goat enterprise (Kumar, 2007). The trend of commercialization has especially been prominent in the state of Tamil Nadu, where demand for marketing and availability of grazing sources is relatively better. Keeping in view the above facts, the present research was designed to study the adoption level of improved goat farming technologies by commercial goat farmers.

\section{Materials and Methods}

Commercial goat farmers were selected fromSalem, Namakkal and Dharmapuri districts from North Western Zone (NWZ) and Thiruchirapalli, Nagapattinam and Thanjavur districts from Cauvery Delta Zone (CDZ) of Tamil Nadu. The agro-climatic zones and districts were selected purposively based on the density and highest population of goats and preliminary information collected regarding commercial goat farming practices, availability of commercial goat farms etc. From each district, 20 commercial goat farmers were chosen randomly and a total of 120 respondents were selected for the present research. The selected commercial goat farmers were post-stratified according to the flock size viz., small (< 50 goats), medium
(51-100 goats) and large category (>100 goats) with their average flock sizes of 37.92, 77.30 and 192.45, respectively. According to Rogers (2003), adoption is the decision to make full use of an innovation as the best course of action available. The level of adoption was operationalized as the extent of which one makes use of the recommended goat farming technologies. The important goat farming technologies were selected in the major areas of housing, feeding, breeding, disease control, and general management practices based on review of literature and by consulting with veterinary and extension experts. The scores were assigned for the adoption of each scientific goat farming technologies in the following way.

The total score for a respondent was obtained by summing up the score obtained on each practice. The adoption level of the respondent was measured by using of adoption index developed by Karthikeyan (1994).

$$
\begin{aligned}
& \text { Respondent's total score } \\
& \text { Adoption Index = -------------------------- X } 100 \\
& \text { Total possible score }
\end{aligned}
$$

Depending upon the extent of adoption of improved technologies, the respondents were categorized as low adopters, medium adopters and high adopters by computing mean and standard deviation. Also, the respondents' adoptions towards different components of scientific goat farming technologies were classified based on frequency and percentage.

Multiple linear regression analysis was applied to analyze the socio-economic factors influencing the adoption level of improved goat farming technologies by commercial goat farmers.The following multiple linear regression models was fitted.

$$
\begin{aligned}
& Y_{a}=\alpha+\beta_{1} X_{1}+\beta_{2} X_{2}+\beta_{3} X_{3}+\beta_{4} X_{4}+\beta_{5} \\
& X_{5}+\ldots \ldots \ldots \ldots \ldots \ldots \ldots \ldots \ldots \ldots+\mu
\end{aligned}
$$


Where,

$\mathrm{Y}_{\mathrm{a}}=$ Adoption level

$\alpha=$ Constant term

$\beta_{\mathrm{i}}{ }^{\prime} \mathrm{s}=$ Regression co-efficients

$\mathrm{X}_{\mathrm{i}}=$ Socio-economic variables

$\mu=$ Random disturbance term; $\left(\mu_{i} \sim 0, \sigma_{i}^{2}\right)$

\section{Results and Discussion}

A perusal of the Table 1 indicates that overall 46.67 per cent of the commercial goat farmers had medium adoption of improved goat farming practices, followed by high $(33.33 \%)$ and low $(20.00 \%)$ extent of adoption. Average adoption indices of improved goat farming technologies were 60.71, 64.61, 76.19 and 67.20 for small, medium, large and overall categories of farmers, respectively.It could be inferred from the findings that the adoption level of improved goat farming technologies determined by the extent of knowledge, resource availability, service availability and flock size, demonstration of efficient technologiesand felt need of the commercial goat farmers. These findings are supported by the findings of Bihari and Singh (2016), Koli and Koli (2016) and Meena et al., (2011).

It is evident from the Table 2 that the adoption index of improved goat housing practices in commercial goat farming indicated highest index score for use of feeding and watering devices (88.75), followed by adoption of recommended floor space for goats (83.33), Orientation (East-West) of goat shed (74.16), drainage facility (72.920 and adoption of slatted floor housing (52.91). Based on the adoption index, improved goat housing practices were ranked. It was observed that different feeding and watering devices for goats used by farmers based on the type of goat shed, local availability of materials, low cost devices; at the same time the farmers were also considered durability of the materials.
From the Table 2 it is evident that feeding colostrums to kids within one hour after birth obtained highest score (79.58) followed by feeding of concentrate at recommended quantity (74.17), flushing prior to breeding (67.50), fodder cultivation practices (65.83) and feeding mineral supplements (46.67). It was observed that majority of the small and medium commercial goat farmers practiced home-made concentrate feed by purchasing raw materials like oil cakes, rice bran, maize, etc. followed by large farmers used readymade commercial concentrate feed. The above findings are similar with the findings reported by Narmatha et al., (2013).

It could be visualized from Table 2 that highest adoption index score was possessed by appropriate age (10-12 months) of breeding in Does (86.67), followed by identification of Does in heat (80.41), changing buck at regular intervals (72.92), pregnancy verification (44.17) and Artificial Insemination (42.50). It was reported by the commercial goat farmers that mounting behavior of Buck and Doe, bleeding and clear discharge from the vulva were the most reliable symptoms for detection of heat in Does. Least adoption of Artificial Insemination $(21.67 \%)$ by the commercial goat farmers was due to the fact that lack veterinary infrastructure facilities, limited availability of trained veterinary doctors and the facility available only in research stations. It can further be seen from Table 2 that the adoption index for health care practices revealed deworming of goats had highest score (82.08) and rank I, followed by vaccination (72.50), isolation of sick animals (66.25), disinfection of farm (65.00) and dipping in ecto-parasiticide (44.17). The findings of the study described that majority of the commercial goat farmers completely adopted deworming $(75.00 \%)$ and vaccination $(55.00 \%)$ in goats shows that the importance of preventive measures realized by the respondents. 
The scores were assigned for the adoption of each scientific goat farming technologies

\begin{tabular}{|l|c|}
\hline Adoption pattern & Score \\
\hline Complete adoption & 2 \\
\hline Partial adoption & 1 \\
\hline Non adoption & 0 \\
\hline
\end{tabular}

Table.1 Distribution of respondents according to extent of adoption level of improved goat farming technologies

\begin{tabular}{|l|c|c|c|c|c|}
\hline $\begin{array}{l}\text { Adopter } \\
\text { category }\end{array}$ & Score index & $\begin{array}{c}\text { Small } \\
\text { farmers } \\
(\mathbf{n = 5 6})\end{array}$ & $\begin{array}{c}\text { Medium } \\
\text { farmers } \\
(\mathbf{n = 4 2})\end{array}$ & $\begin{array}{c}\text { Large } \\
\text { farmers } \\
(\mathbf{n = 2 2})\end{array}$ & $\begin{array}{c}\text { Overall } \\
\mathbf{N}=120\end{array}$ \\
\hline Low adopters & $<54.59$ & $13(23.21)$ & $9(21.43)$ & $2(9.09)$ & $24(20.00)$ \\
\hline $\begin{array}{l}\text { Medium } \\
\text { adopters }\end{array}$ & $54.59-79.81$ & $28(50.00)$ & $22(52.38)$ & $6(27.27)$ & $56(46.67)$ \\
\hline High adopters & $>79.81$ & $15(26.79)$ & $11(26.19)$ & $14(63.64)$ & $40(33.33)$ \\
\hline \hline Mean \pm SD & $67.20 \pm 12.61$ & & & & \\
\hline Mean adoption index & & $\mathbf{6 0 . 7 1}$ & $\mathbf{6 4 . 6 1}$ & $\mathbf{7 6 . 1 9}$ & $\mathbf{6 7 . 2 0}$ \\
\hline
\end{tabular}

Table.3 Overall adoption of goat husbandry technologies by commercial goat farmers

\section{Practices}

A. Housing

B. Feeding

C. Breeding

D. Health care

E. General management

\begin{tabular}{|c|c|c|}
\hline Obtained score & Adoption index & Rank \\
\hline 893 & 74.41 & I \\
\hline 809 & 67.42 & II \\
\hline 784 & 65.33 & IV \\
\hline 792 & 66.00 & III \\
\hline 754 & 62.81 & V \\
\hline
\end{tabular}


Table.2 Practice wise distribution of respondents according to the adoption of improved goat farming technologies

\begin{tabular}{|c|c|c|c|c|c|c|}
\hline \multirow{2}{*}{ Sl. No. } & \multirow{2}{*}{ A. Housing } & \multicolumn{3}{|c|}{ Adoption ( $\mathrm{N}=120)$} & \multirow{2}{*}{$\begin{array}{l}\text { Adoption } \\
\text { index }\end{array}$} & \multirow[t]{2}{*}{ Rank order } \\
\hline & & $\mathrm{CA}$ & PA & NA & & \\
\hline 1. & Recommended floor space for goats & $88(73.33)$ & $24(20.00)$ & $8(6.67)$ & 83.33 & II \\
\hline 2. & Orientation (E-W) of goat shed & $70(58.33)$ & $38(31.67)$ & $12(10.00)$ & 74.16 & III \\
\hline 3. & Use of feeding and watering devices & $98(81.67)$ & $17(14.17)$ & $5(4.16)$ & 88.75 & I \\
\hline 4. & Adoption of slatted floor housing & $51(42.50)$ & $25(20.83)$ & $44(36.67)$ & 52.91 & V \\
\hline \multirow[t]{2}{*}{5.} & Proper drainage facility & $72(60.00)$ & $31(25.83)$ & $17(14.17)$ & 72.92 & IV \\
\hline & B. Feeding & & & & & \\
\hline 1. & Feeding of concentrates at recommended quantity & $84(70.00)$ & $10(8.33)$ & $26(21.67)$ & 74.17 & II \\
\hline 2. & Feeding mineral supplements & $39(32.50)$ & $34(28.33)$ & $47(39.17)$ & 46.67 & V \\
\hline 3. & Flushing prior to breeding & $63(52.50)$ & $36(30.00)$ & $21(17.50)$ & 67.50 & III \\
\hline 4. & Colostrum feeding to kids ( $<1 \mathrm{hr}$. after birth) & $82(68.33)$ & $27(22.50)$ & $11(9.17)$ & 79.58 & I \\
\hline \multirow[t]{2}{*}{5.} & Fodder cultivation practices & $68(56.67)$ & $22(18.33)$ & $30(25.00)$ & 65.83 & IV \\
\hline & C. $\quad$ Breeding & & & & & \\
\hline 1. & Identification of Does in heat & $80(66.67)$ & $33(27.50)$ & $7(5.83)$ & 80.41 & II \\
\hline 2. & Pregnancy verification & $38(31.67)$ & $30(25.00)$ & $52(43.33)$ & 44.17 & IV \\
\hline 3. & Artificial Insemination (AI) & $26(21.67)$ & $50(41.66)$ & $44(36.67)$ & 42.50 & V \\
\hline 4. & Appropriate age of breeding in Does & $95(79.17)$ & $18(15.00)$ & $7(5.83)$ & 86.67 & I \\
\hline \multirow[t]{2}{*}{5.} & Changing buck at recommended intervals & $76(63.33)$ & $23(19.17)$ & $21(17.50)$ & 72.92 & III \\
\hline & D. Disease control & & & & & \\
\hline 1. & Deworming & $90(75.00)$ & $17(14.17)$ & $13(10.83)$ & 82.08 & I \\
\hline 2. & Dipping & $37(30.83)$ & $32(26.67)$ & $51(42.50)$ & 44.17 & V \\
\hline 3. & Vaccination & $66(55.00)$ & $42(35.00)$ & $12(10.00)$ & 72.50 & II \\
\hline 4. & Farm disinfection & $60(50.00)$ & $36(30.00)$ & $24(20.00)$ & 65.00 & IV \\
\hline \multirow[t]{2}{*}{5.} & Isolation of sick animals & $64(53.33)$ & $31(25.83)$ & $25(20.83)$ & 66.25 & III \\
\hline & E. General management & & & & & \\
\hline 1. & Weaning & $83(69.17)$ & $22(18.33)$ & $15(12.50)$ & 78.33 & I \\
\hline 2. & Tagging & $69(57.50)$ & $31(25.83)$ & $20(16.67)$ & 70.41 & III \\
\hline 3. & Hoof trimming & $12(10.00)$ & $25(20.83)$ & $83(69.17)$ & 20.41 & V \\
\hline 4. & Farm record maintenance & $75(62.50)$ & $30(25.00)$ & $15(12.50)$ & 75.00 & II \\
\hline 5. & Castration of kids & $77(64.17)$ & $14(11.67)$ & $29(24.17)$ & 70.00 & IV \\
\hline
\end{tabular}

(Figures in the parenthesis indicate percentage); CA-Complete Adopters, PA-Partial Adopters, NA-Non Adopters 
Table.4 Factors influencing the adoption of improved technologies by commercial goat farmers

\begin{tabular}{|c|c|c|c|c|}
\hline Sl. No. & Independent variables & 'b' & S.E.(b) & 't' value \\
\hline \multicolumn{2}{|c|}{ Constant } & 1.346 & & \\
\hline $\mathbf{X}_{1}$ & Age & 0.027 & 0.073 & 0.308 \\
\hline $\mathrm{X}_{2}$ & Gender & 0.017 & 1.620 & 0.47 \\
\hline $\mathbf{X}_{\mathbf{3}}$ & Education & $0.116 *$ & 0.658 & 1.997 \\
\hline $\mathbf{X}_{4}$ & Family size & 0.029 & 0.405 & 0.344 \\
\hline $\mathbf{X}_{\mathbf{5}}$ & Family type & -0.70 & 1.330 & -0.762 \\
\hline $\mathrm{X}_{6}$ & Occupation & 0.012 & 0.416 & 0.247 \\
\hline$\overline{\mathbf{X}_{\mathbf{7}}}$ & Income & $0.683 * *$ & 0.026 & 6.637 \\
\hline $\mathbf{X}_{8}$ & Experience in goat farming & -0.004 & 0.057 & -0.180 \\
\hline $\mathrm{X}_{9}$ & Livestock possession & -0.019 & 0.105 & -0.391 \\
\hline $\mathbf{X}_{10}$ & Land holding & $0.338 *$ & 0.248 & 2.095 \\
\hline $\mathbf{X}_{11}$ & Investment & $0.527 * *$ & 0.017 & 4.082 \\
\hline $\mathbf{X}_{12}$ & Flock size & $0.659 * *$ & 0.008 & 9.516 \\
\hline $\mathbf{X}_{13}$ & Social participation & -0.043 & 0.057 & -1.887 \\
\hline$\overline{X_{14}}$ & Contact with extension agency & 0.031 & 0.060 & 1.202 \\
\hline $\mathbf{X}_{15}$ & Training on goat farming & $0.256^{*}$ & 0.159 & 2.178 \\
\hline $\mathbf{X}_{16}$ & Economic motivation & $0.392 * *$ & 0.166 & 5.742 \\
\hline $\mathbf{X}_{17}$ & System of management & $0.782 *$ & 0.071 & 2.023 \\
\hline \multicolumn{5}{|c|}{$\mathbf{R}^{2}=0.762$ Adjusted $\mathbf{R}^{2}=0.736 \mathrm{~F}=22.93 *$} \\
\hline \multicolumn{5}{|c|}{$\begin{array}{l}* * \text { - Significant at } 0.01 \text { level of probability } \\
* \text { - Significant at } \mathbf{0 . 0 5} \text { level of probability }\end{array}$} \\
\hline
\end{tabular}

Dipping of goats to prevent ecto-parasites infestation is a very important activity which has been least concerned by the respondents; in disease prevention faction. It is recommended that the goat farmers need to be sensitized about dipping and other needy technologies for disease prevention through training, awareness, demonstration by the extension agencies in the study areas.

Regarding general management practices (Table 2) adopted by the farmers, weaning of kids (78.33) had higher adoption index score followed by farm record maintenance(75.00), tagging (70.41), castration of kids (70.00) and hoof trimming (20.41). This is in agreement with the findings of Singh et al., (2017); Suresh and Vasanthakumar (2017) who reported that castration of male had fewer adoption score and weaning of kids had higher adoption score, respectively. Kumar (2007) reported in his study on commercial goat farming in India that, overall 6.00 per cent of the commercial goat farmers had adopted hoof trimming, 67.00 per cent adopted tagging of kids for identification and 72.00 per cent and 50.00 per cent of them had awareness and adoption of farm record maintenance, respectively.

Overall adoption of improved goat husbandry practices by commercial goat farmers

Overall adoption index of improve goat husbandry practices by the commercial goat farmers presented in the Table 3 reveals that housing practices obtained highest adoption index (74.41) followed by feeding (67.42), health care (66.00), breeding (65.33) and 
general management practices (62.81). These findings differ with the results of Roy and Tiwari (2017), Narmatha et al., (2013) and Nepali et al., (2010) who reported that the overall adoption behavior of traditional goat farmers was only less than 50.00 per cent. The results of the study clearly differentiate the adoption behavior of traditional and commercial goat farmers.

The factors influencing the adoption level were portrayed in Table 4 . The results revealed that the value of co-efficient of multiple determination $\left(\mathrm{R}^{2}\right)$ was 0.762 , indicating 76.20 per cent of variation in adoption level of commercial goat farmers which was due to the combined influence of all the selected independent variables (Table 4). The regression analysis also described that the variables, family income, investment in goat farming, flock size and economic motivation had positive and significant (1\% level) influence on the variability in adoption level of commercial goat farmers. Variables viz., education, land holding, training on goat farming and system of management showed positive and significant (5\%level) towards adoption level of commercial goat farmers. These findings are in agreement with the findings of Guntoro et al., (2016) and Kumar (2014).

The results of the present study indicated that the level of technology adoption by commercial goat farmers was medium to high and is highly influenced by family income, flock size of the farm (number of goats), investment on goat farming, economic motivation, followed by education, land holding, training on goat farming and system of management of goats. Based on the mean adoption index, the findings revealed that, small commercial goat farmers are low adopters as compared to medium and large farmers. Hence, the study recommends that innovations in technological interventions on scientific goat farming shall be supported with vocational training, demonstration of efficient technologies and motivating the commercial goat farmers to optimize the flock size with extension support and services might help them to adopt recommended improved technologies and sustainable goat production thereby enhancing the farmers' livelihood.

\section{References}

Annual report. 2015-16. ICAR-Central Institute for Research on Goats (CIRG), Makhdoom, Madhura, U.P.

Bihari, Shyam and Singh, Narpat. 2016. Adoption of goat farming technologies by the farmers in Udaipur district of Rajasthan. Res. J. Animal Hus. \& Dairy Sci., 7(2): 75-79.

Guntoro, B. Rakhman, A.N. and Suranindyah Y.Y. 2016. Innovation adoption of dairy goat farmers in Yogyakarta, Indonesia. International Journal of Environmental \& Agriculture Research, 2(2): 98-109.

Koli, R.T. and Koli, S.R. 2016. Extent of adoption of goat farming technologies and problems faced by goat keepers in adoption of goat farming technology. Research Journal of Animal Husbandry and Dairy Science, 7(1): 35-38.

Kumar, R., Singh, B.P., Kumar, V., Kumar, S and Maousami. (2014). Adoption of health technologies among goat farmers indifferent agro-climatic zones of Bihar. J. of Applied Animal Res., DOI: 10.1080/09712119.2014.888002.

Kumar, S. 2007. Commercial goat farming in India: An emerging agri-business opportunity. Agricultural Economics Research Review, 20: 503-520.

Meena, M.L., Singh, H.C., Aishwarya, D., Ajay Kumar and Chauhan, S.V.S. 2011. Goat keepers' adoption about improved goat production practices. Indian Res. $J$. Ext. Edu. 11(1): 39-43. 
Narmatha, N., Sakthivel, K. M., Uma, V. and Akila, N. 2013. Adoption and constraints in improved goat rearing practices. Indian J. Anim. Res., 47(6): $547-550$

Nepali, M.B., Sudha, S., Sujaya, U., Bhoj Raj, P., Sharma, B., Hari Prasad, D. and Sabita, M. A. 2010. Adoption of goat production technology at the farm level. Nepal Journal of Science and Technology, 11: 79-82.

Roy, R and Tiwari, R. 2017. Farmers' knowledge and adoption level on goat healthcare management practices in selected areas of India. Bang. J. Anim. Sci., 46(2): 95-101.

Singh, N.P and Shalander Kumar. 2007. An alternative approach to research forharnessing production potential of goats. Proceedings of $4^{\text {th }}$ National Extension Congress, Jawaharlal Nehru Krishi Vishwavidyalaya, Jabalpur, 9-11 March.

Singh, S.K., Singh, R., Kushram, P and Viswkarma, R. 2017. Adoption level of scientific goat farming practices among goat farmers. Asian Journal of Agricultural Extension, Economics \& Sociology, 21(4): 1-6.

Suresh Kumar, P and Vasanthakumar, P. 2017. Adoption of improved scientific goat rearing practices in Tamil Nadu. Indian Journal of Small Ruminants. 23(1): 136-138

\section{How to cite this article:}

Gunaseelan, M., B.P. Singh, Med Ram Verma and Pachaiyappan, K. 2018. Adoption Level of Improved Goat Farming Technologies by Commercial Goat Farmers in Tamil Nadu, India. Int.J.Curr.Microbiol.App.Sci. 7(05): 3293-3300. doi: https://doi.org/10.20546/ijcmas.2018.705.385 